\title{
DUMPING SOCIAL: CONCORRÊNCIA DESLEAL X DIREITOS FUNDAMENTAIS
}

\author{
SOCIAL DUMPING: UNFAIR COMPETITION X FUNDAMENTAL RIGHTS
}

\author{
JOÃO MARCELO DE LIMA ASSAFIM ${ }^{1}$ \\ SANDRO MANSUR GIBRAN ${ }^{2}$ \\ TAMARA CRISTIANE GEISER ${ }^{3}$
}

\section{RESUMO}

O presente trabalho tem o escopo de tratar sobre o dumping social, a fim de averiguar os danos ocorridos aos direitos fundamentais dos trabalhadores no âmbito da prática de concorrência desleal. Será explanado acerca da evolução do comércio e do trabalho na esfera internacional, delineando os principais aspectos do dumping e das medidas antidumping. Por fim, será abordado o dumping social, apresentando a cláusula social como instrumento que busca obstar tal prática, demonstrando os debates existentes na doutrina sobre o tema. A metodologia a ser utilizada será através de pesquisa de natureza teórico-bibliográfica, com uso do método indutivo, por meio de análise da doutrina e de documentos internacional que versam sobre o assunto.

Palavras-chave: Dumping social, cláusula social, direitos trabalhistas.

\footnotetext{
${ }^{1}$ Doctor en Derecho Mercantil - Universidad de Santiago de Compostela. ESPANHA, Re. Doutor em Direito Comercial Universidade de São Paulo USP, Professor Adjunto da Faculdade Nacional de Direito da UFRJ. Diretor do Programa de Mestrado em Direito da UCAM, Professor da Academia da Inovação do INPI, Professor do Doutorado em Propriedade Intelectual e Desenvolvimento do IE UFRJ / FIOCRUZ.

${ }^{2}$ Doutor em Direito Econômico e Socioambiental pela Pontifícia Universidade Católica do Paraná (2009). Mestre em Direito Social e Econômico pela Pontifícia Universidade Católica do Paraná (2003). Graduado em Direito pela Faculdade de Direito de Curitiba (1996). É advogado. Professor de Direito Empresarial junto ao Centro de Estudos Jurídicos do Paraná CEJPR e na Escola da Magistratura Federal do Paraná ESMAFE/PR. Professor visitante na Universidade da Indústria da Federação das Indústrias do Estado do Paraná UNINDUS. Coordenador do Curso de Pós-Graduação em Direito Empresarial do UNICURITIBA. Coordenador do Curso de Pós-Graduação em Direito Contratual do UNICURITIBA. Professor permanente no Programa de Mestrado e Doutorado em Direito Empresarial e Cidadania do UNICURITIBA.

${ }^{3}$ Advogada. Especialista e Direito Constitucional e Direito do Trabalho e Processo de Trabalho. Mestranda em Direito Empresarial e Cidadania pelo Centro Universitário de Curitiba.
} 


\begin{abstract}
The purpose of this paper is to deal with social dumping in order to investigate the damage to the fundamental rights of workers under unfair competition. It will be explained about the evolution of trade and labor in the international sphere, outlining the main aspects of dumping and anti-dumping measures. Finally, social dumping will be addressed, presenting the social clause as an instrument that seeks to prevent such practice, demonstrating the existing debates in the doctrine on the subject. The methodology to be used will be through theoretical and bibliographical research, using the inductive method, through doctrine analysis and international documents on the subject.
\end{abstract}

Key-words: Social dumping, social clause, labor rights.

\title{
INTRODUÇÃO
}

O presente trabalho traz uma análise do dumping social e da proposta cláusula social que se apresenta como instrumento para coibir as violações referentes à concorrência desleal e aos direitos trabalhistas.

A relevância do tema se insere na problemática internacional de concorrência desleal praticada através do dumping social.

O dumping social consiste na busca de vantagens de custo mais baixo de produção, através do reduzido valor de mão-de-obra, com salários baixos e condições precárias de trabalho, a fim de alcançar valores mais competitivos de mercado.

A conduta é considerada como ato desleal de concorrência e, ainda, como afronta aos direitos sociais, resultando em ilícito que pode ser punível em âmbito internacional.

Existe a proposição para se implementar a cláusula social nas transações comerciais internacionais, como instrumento para solucionar esta problemática.

Todavia, considerando a bivalência do tema, por envolver comércio e direitos trabalhistas, a cláusula social ainda é muito debatida na esfera internacional, uma vez que envolve dissonância desde a competência de sua fiscalização e punibilidade, até a destinação de valores com fins reparatórios do dano.

No primeiro capítulo será tratado da evolução do comércio e do trabalho no campo internacional.

No segundo capítulo abordaremos o dumping e as medidas antidumping.

No terceiro capítulo será explorada a temática do dumping social e seus reflexos, trazendo conceito e o movimento internacional que traz o assunto em voga. 
E, por fim, enfrentar-se-á especificamente o tema da cláusula social, com a abordagem do instrumento e apresentando os debates favoráveis e contra que tocam o assunto.

A metodologia a ser utilizada será através de pesquisa de natureza teórico-bibliográfica, utilizando-se o método indutivo, com a análise da doutrina e de documentos internacional que versam sobre o assunto.

\section{EVOLUÇÃO DO COMÉRCIO E DO TRABALHO NO CAMPO INTERNACIONAL}

O comércio internacional evoluiu ao longo dos séculos, sofrendo os efeitos da globalização, principalmente no que se refere ao território e à escala de produção.

Em 1944 o sistema financeiro internacional estava em ruínas e as maiores potências mundiais se encontravam em guerra, com os olhos voltados aos avanços bélicos (FRANCO, 2006, p. 122).

O cenário da grande depressão, que foi fruto dos acontecimentos de 1929, gerou forte diminuição do comércio e resultou em elevado número de desemprego, o que gerou diversas políticas protecionistas nas grandes potências, principalmente nos Estados Unidos da América.

Neste contexto histórico é que 44 países, dentre eles o Brasil, reuniram-se na cidade de Bretton Woods, no estado de New Hampshire, nos Estados Unidos da América, para a Conferência Monetária e Financeira das Nações Unidas, com o objetivo de reconstruir o capitalismo mundial e criar regras que regulassem a política econômica internacional (BARRETO, 2009).

Após a $2^{\mathrm{a}}$ Guerra Mundial o comércio internacional passou a ser visto pelos países como um instrumento para a recuperação do progresso, o que era um das principais motivações de conferências internacionais daquela época.

Os acordos elaborados na Conferência de Bretton Woods criaram o Fundo Monetário Internacional (FMI), o Banco Internacional para a Reconstrução e Desenvolvimento (BIRD ou Banco Mundial) e a Organização Internacional do Comércio (OIC) (FRANCO, 2006, p. 122).

Em 1948 foi elaborada a Carta de Havana, a qual, embora não tenha entrado em vigor, descrevia que "o comércio poderia ser um mecanismo de promoção da riqueza no mundo" (GAVA, 2008, p. 48).

A Carta de Havana não conseguiu aprovação no Congresso Americano, e isso faria com que este país não estivesse inserido no acordo e, em se tratando de uma nação líder da economia mundial, não era interessante a aprovação do referido documento. 
Por outro lado, da Conferência de Bretton Woods subsistiu o Acordo Geral de Tarifas e Comércio - GATT, o qual tratou de estabelecer negociações de acordos multilaterais de redução recíproca de tarifas e da criação de cláusulas gerais concernentes à redução de tarifas.

O fato de a Carta de Havana não ter entrado em vigor constituiu grande perda, pois em seu texto havia a previsão de considerar algumas violações aos direitos dos trabalhadores e a inclusão de uma cláusula social, que teria sido discutida na Conferência da ONU sobre Comércio e Emprego.

O texto normativo previa o seguinte:

Art. $7^{\circ}$. Os Membros reconhecem (...) que todos os países têm um interesse comum no alcance e manutenção de padrões trabalhistas justos, relacionados à produtividade, além da melhoria das condições salariais e de trabalho que a produtividade permitir. ... Reconhecem que condições injustas de trabalho, particularmente na produção para exportação, criam dificuldades para o comércio internacional, e, dessa forma, cada Membro deve tomar todas as ações que sejam apropriadas e razoáveis para eliminar tais condições dentro do seu território.

Membros que sejam também Membros da Organização Internacional do Trabalho (OIT) devem cooperar com aquela organização para dar efeito a esse compromisso.

Em todas as questões relacionadas com direitos trabalhistas que forem referidas à Organização (...), esta deve consultar e cooperar com a $\mathrm{OIT}^{4}$.

Em que pese a Carta de Havana não tenha sido aprovada, ao menos se estabeleceu um aspecto dos direitos dos trabalhadores pelo GATT, que trata das Exceções Gerais, que permitiu aos governos que banissem o comércio de produtos que fossem advindos de trabalho de presos.

Em diversas rodadas de negociações do GATT, embora tenham sido levantadas questões trabalhistas, não se chegou a consenso entre os países, o que fez o sistema internacional concentrasse temas, essencialmente, comerciais, sem muita consistência às questões trabalhistas (FRANCO, 2006, p. 125).

Dentre as rodadas de negociação do GATT, a Rodada Uruguai foi a mais significativa no âmbito da economia mundial, uma vez que resultou na criação da Organização Mundial do Comércio (OMC).

Enquanto o GATT era apenas um acordo, a OMC é um organismo internacional que administra acordos multilaterais relacionados ao comércio de bens.

4 GRANGER, Clotilde; SIROEN, Jean-Marc. Core Labor Standards in Trade Agreements. From Multilateralism to Bilateralism. Université Paris Dauphine, Département d'Économie Appliqué. Disponível em: <http://www.iddri.org/Activites/Conferences-internationales/21102005_CAT\&E_siroen_com.pdf>. Acesso em: 11.Set.2019. 
Inicialmente os EUA se opuseram à criação da $\mathrm{OMC}$, pois tinham receio de que suas normas pudessem colidir com a estrutura jurídica americana relativa a represálias comerciais a países que consideraram desleais em comércio exterior. No entanto, em 1994 os EUA aderiram à Organização e, o Brasil também, com aprovação da Câmara e do Senado.

A OMC trouxe inovações ao GATT, como a criação do Órgão de Solução de Controvérsias (OSC), como órgão para a solução de conflitos econômicos de âmbito internacional.

O OSC apresenta uma estrutura mais complexa, com a fixação de prazos para a constituição e o funcionamento de painéis, bem como a elaboração de relatórios e para apresentação de defesa e de apelação, obstando a tomada de medidas de forma unilateral. E, assim, em julgamentos, determina que o Estado vencido seja obrigado a oferecer uma compensação ou ajustar sua política comercial ao relatório aprovado.

\section{DUMPING}

O dumping consiste em uma prática comercial, através da qual uma empresa passa a vender mercadorias em preço inferior ao do mercado interno, com o objetivo de eliminação da concorrência.

A expressão de língua inglesa traz a idéia de jogar algo fora, despejar ou descarregar e não se confunde com subsídios ou prática anticoncorrencial de discriminação de preço interno (CASAGANDE, 2014, p. 11).

De acordo com o artigo VI, item 1, do GATT, dumping pode ser conceituado como:

1. As partes contratantes reconhecem que o dumping, pelo qual os produtos de um país são introduzidos no comércio de outro país por menos que o valor normal dos produtos, deve ser condenado se causa ou ameaça causar um prejuízo material a uma indústria estabelecida no território de Parte Contratante ou retarda substancialmente o estabelecimento de uma indústria nacional. Para efeitos do presente artigo, o produto deve ser considerado como sendo introduzido no comercio de um país importador, por menos que seu valor normal, se o preço do produto exportado de um país para outro (a) é inferior ao preço comparável, no decurso de operações comerciais para o produto similar quando destinado ao consumo no país exportador, ou, (b) na falta de preço no mercado interno, é inferior a (i) o maior preço comparável de um produto similar para exportar para qualquer país terceiro, no decurso de operações comerciais ou (ii) o custo de produção do produto no país de origem mais um acréscimo razoável para cobrir custos e lucros (ANTUNES, 2014, p. 12-13). 
Catarina Frahm e Marco Antônio César Villatore buscaram a definição do termo dumping da seguinte forma:

A expressão dumping provém do verbo inglês dump, significando desfazer-se de algo e depositá-lo em determinado local, como se fosse lixo. No mercado internacional uma empresa executa dumping quando: (a) detém certo poder de estipular preço de seu produto no mercado local (empresa em concorrência imperfeita); e (b) perspectiva de aumentar o lucro por meio de venda no mercado internacional. Essa empresa, então, vende no mercado externo seu produto a preço inferior ao vendido no mercado local, provocando elevada perda de bem-estar ao consumidor nacional, porque os residentes locais não conseguem comprar o produto a ser vendido no estrangeiro (FRAHM; VILLATORE, 2011).

Tanto a natureza quanto a finalidade de sua prática, concentram-se no âmbito econômico do negócio, sendo que o avanço do dumping é resultado da expansão industrial e da globalização. Tal realidade reflete de forma negativa diretamente na deteriorização da ética no comércio internacional.

Depreende-se do conceito de dumping que se trata de uma forma de concorrência desleal podendo ser distinguido em dois aspectos. O primeiro aspecto versa sobre o âmbito interno, com a venda de mercadorias abaixo do preço de custo, de maneira injustificada e, o segundo aspecto vislumbra o âmbito internacional, com a venda de produtos ao exterior em valor menor ao normal praticado em determinado mercado interno (RATTI, 2001, p. 399).

Não obstante a esses aspectos distintos, existe uma conceituação diferenciada que toma por base as medidas impeditivas da prática do dumping, abarcando aspectos jurídicos, econômicos e políticos (BARRAL, 2000, p. 16-71).

A definição na esfera jurídica trata do próprio Acordo Antidumping, onde prevê a prática de dumping como a oferta de produto no comércio de outro país a preço inferior a seu valor normal, no caso de o preço de exportação do produto ser inferior àquele praticado, no curso normal das atividades comerciais, para o mesmo produto quando destinado ao consumo no país exportador.

No que toca à definição econômica, consideram-se os fundamentos de aplicação das medidas antiduming, que está na necessidade de medidas protetivas da indústria nacional, diante da concorrência desleal exterior. 
Por fim, a concepção política consiste a tentativa de explicar o fenômeno como um meio termo entre a liberalização econômica e proteção do mercado nacional e como instrumento de retaliação estatal no plano internacional (ROCHA DA SILVA, 2005, p. 4).

Essas acepções e definições distintas destacam a complexidade do instituto a fim de se construir uma sentença genérica para tanto. $\mathrm{O}$ que se pode extrair, no entanto, é a premissa de que todos os conceitos aportam na prática de concorrência desleal, mediante a introdução de produto no mercado interno em valor inferior ao praticado regionalmente, com o fito de causar dano à indústria local (MARQUES, 1998, p. 299).

\subsection{Os direitos antidumping}

A prática do dumping é antiga, havendo um dado momento histórico que os Estados Unidos da América o realizavam com muita freqüência, o que incentivou o Canadá a adotar o Act to Amend the Customs, em 1904.

O contexto de criação daquela normativa se deu quando da construção de uma ferrovia que tinha o escopo de facilitar o tráfego de pessoas e de mercadorias em seu território. Algumas empresas americanas vendiam aço a preço menor que o executado no mercado interno do Canadá, o que impedia a concorrência da indústria local (TEIXEIRA, 2012, p. 111).

De um lado os fazendeiros buscavam a redução de tarifas junto ao governo e, de outro lado as indústrias pleiteavam a manutenção das tarifas elevadas. A manutenção de tarifas elevadas estava prejudicando as indústrias de aço nacional, porém, por questões políticas o governo não poderia perder o apoio político dos fazendeiros.

Com isso, emerge a primeira lei antidumping que justificou o aumento tarifário do aço, como medida de defesa comercial. A inovação da disposição normativa preconizava a imposição de taxas equivalentes à diferença do preço interno e o preço do país exportador, sem considerar se o país sofreria ou não com a exportação (CASAGANDE, 2014, p. 5).

A par desse quadro sociopolítico, anos depois, com as rodadas de negociações do GATT, a preocupação mundial com o tema tornou-se pauta.

Assim, o Artigo VI, do Acordo Geral Sobre Tarifas Aduaneiras e Comércio 1947 (GATT 47) passou a figurar como fonte primordial sobre o tema e se destinou ao regramento dos direitos antidumping e de compensações ${ }^{5}$.

\footnotetext{
5 Acordos da OMC. Disponível em: <http://www.mdic.gov.br/index.php/comercio-exterior/negociacoesinternacionais/1885-omc-acordos-da-omc>. Acesso em: 12.Set.2019.
} 
Existe uma discussão doutrinária que repercute na natureza jurídica dos direitos antidumping. Não há definição própria, sendo que as principais o classificam como instituto de natureza aduaneira, um meio de intervenção no domínio econômico de natureza não tributária, como sanção, como instituto de natureza sui generis; e/ou um instituto de natureza tributária.

Os direitos antidumping podem ser definidos como um montante em dinheiro, igual ou inferior à margem de dumping apurada, que é exigido a fim de afastar os efeitos danosos à indústria doméstica, decorrentes de importações realizadas a preço a menor ao de mercado.

As maneiras de se calcular o dumping, geralmente são duas: (i) transaction-totransaction, que compara o preço de exportação com o valor normal relativa a cada transação comercial; (ii) average-to-average, que compara o valor normal médio ponderado com o preço médio ponderado de todas as operações de exportações equivalente (LÔBO, 2007).

Como se nota as medidas antidumping regulamentadas se concentram na compensação pecinuária a fim de compensar economicamente aquele que sofreu o dano financeiro, em razão da prática de concorrência desleal.

\section{DUMPING SOCIAL E SEUS REFLEXOS}

Considerando o teor predatório do dumping, é notável que a sua repercussão possa alcançar esferas transindividuais e difusas.

O dumping social representa o descumprimento da legislação e de preceitos fundamentais trabalhistas, como instrumento de ampliação dos lucros e de angariar vantagens contra a concorrência empresarial.

Configura atividade de concorrência desleal atingindo o trabalhador e a sociedade de modo geral, conforme preconiza Jorge Luiz Souto Maior (2014, p. 20):

Não estamos, pois, tratando de mera delinquência patronal, de um ato que tenha repercussão apenas nas esferas individuais do agressor e o ofendido, ainda que receba repúdio social. Trata-se de uma prática organizada, deliberada, que atinge, reflexamente, o sistema econômico, com prejuízo difuso para toda a sociedade.

Para além da exploração do trabalhador e seus direitos fundamentais, a sociedade é atingida no âmbito de sua estrutura democrática, a qual deve ser pautada pela justiça social.

A título exemplificativo, o fechamento forçado de uma empresa, diante de uma prática de concorrência desleal, afeta os postos de trabalho dos funcionários da empresa que encerra 
suas atividades, assim como deixa a clientela desta com poucas opções de fornecedor de matéria prima ou até mesmo de produto final.

Não obstante a tais constatações danosas, as demais empresas atuantes na economia também se vêem prejudicadas, pois arcam com o custo mais elevando para cumprir os deveres trabalhistas. Inevitavelmente, a reação contrária também pode ser observada, isto é, diante da concorrência desleal, abre-se o mercado à possibilidade de as outras empresas também passarem a precarizar as condições de trabalho de seus empregados, com o argumento de meramente acompanharem as tendências mercadológicas.

As extensões do dumping se afiguram em seus efeitos colaterais - sociais e jurídicos produzidos pela prática de dumping em sua essência (RODRIGUES PINTO, 2011, p. 6), ou seja, o conteúdo do dumping social seria a deterioração da ordem social pelos efeitos econômicos do dumping.

Além dessas questões dos efeitos quanto ao desemprego e ao mercado econômico, o dumping social também pode ser entendido como a prática de salários baixos e condições de trabalho precárias, o que resulta na redução do preço do produto final, gerando valores de mercadorias reduzidos e competitivos (BARRAL, 2000, p. 10).

Pode-se entender como a busca de empresas por vantagens de custo mais baixo referente à mão-de-obra e a tributos, através da fixação de salários reduzidos, até mesmo com a mudança de trabalhadores de localidades a fim de alcançarem melhores condições de vida.

Trata-se da vantagem comparativa dos países desenvolvidos, frente aos países em desenvolvimento, na empreitada pelo menor custo da mão-de-obra. Esta vantagem é considerada "injusta" pelos protecionistas quando, na realidade, tal custo mais baixo é decorrente da própria situação do estágio de desenvolvimento e, muitas vezes, da miséria mundial (GOYOS JUNIOR, 1995).

Com a assinatura do Tratado de Versales, em 1919, após o fim da Primeira Guerra Mundial, criou-se a Organização Internacional do Trabalho (OIT), o que foi resultado de movimentos sindicais, passando a ser responsável pela formulação e aplicação das normas internacionais do trabalho, mediante documentos internacionais.

Sobre a atuação da OIT, assim preceitua a doutrina:

Os preceitos da OIT - sua Constituição e suas Convenções - tornam-se o modelo da regulação das relações de trabalho e do estabelecimento dos direitos sociais, fixando-se na base da construção do Estado do Bem Estar Social. É, efetivamente a partir da criação dessa Organização, que os Estados adotam, mais sistematicamente, normas e medidas de 
proteção ao trabalhador, tanto no nível constitucional (a partir de então, de caráter social) quanto no infraconstitucional. Os direitos ao trabalho; a salário justo e equitativo; ao descanso (intra e inter-jornada; semanal e anual); à liberdade sindical; à negociação coletiva e à greve, além dos relativos à seguridade social, são contemplados nos ordenamentos nacionais. Em principio, encontra-se completo o quadro dos direitos laborais como mínimo indispensável à salvaguarda da dignidade do trabalhador, conquanto não garantidamente respeitados (CECATO, 2007).

Com efeito, a observância dos direitos sociais, passa a ser obrigação moral dos Estados, diante da impositividade estabelecida nos preceitos da OIT, de maneira que estes devem obedecer à legislação interna e internacional no que toca aos direitos humanos e fundamentais do bem-estar do trabalhador.

Contudo, como visto anteriormente, a prática de dumping social afronta todos os aspectos atinentes às condições de trabalho a fim de observar os parâmetros dos direitos fundamentais.

O contraponto que se faz é a maneira de fiscalização e punibilidade contra os praticantes do dumping social.

Considerando que o dumping - sui generis - é punível através de valores compensatórios destinados àquele que sofreu o prejuízo econômico monetário, e tendo em vista que o prejuízo do dumping social atinge toda a sociedade, de que maneira poderia ser reparado o dano social, além da questão concorrencial latente?

Diante da habitualidade da prática, a temática foi inserida em pauta perante a Organização Mundial do Comércio (OMC), com vistas à questão dos direitos humanistas das relações sociais, sendo debatido com o incentivo de implementação de uma cláusula social.

\section{CLÁUSULA SOCIAL}

O instrumento que se apresenta no cenário mundial é a cláusula social, a qual busca minimizar as práticas desleais que afrontam os direitos trabalhistas nas relações comerciais.

Trata-se de medida antidumping social de maneira preventiva. Porém, o assunto tem gerado debate controvertido inclusive no âmbito da OMC e da OIT.

A cláusula social seria uma solução para tentar manter os padrões trabalhistas mínimos, consoante leciona a doutrina: 
A cláusula social é a imposição de normas em tratados internacionais de comércio internacional que objetivam assegurar a proteção ao trabalhador, estabelecendo padrões mínimos a serem observados pelas normas que regulam o contrato de trabalho nos processos de produção de bens destinados à exportação (ROCHA, 2002, p. 326).

Versa sobre uma tentativa de estabelecer uma ligação entre a relação comercial com as relações sociais.

De acordo com Amaral Junior (1999), essa ligação envolve quatro dimensões. A primeira delas destaca a preocupação com as práticas desleais de comércio. A segunda dimensão se refere à busca de soluções que reduzam os níveis de desemprego nas economias que sofrem os reflexos da globalização. $O$ terceiro viés consiste na tentativa de obstar a expansão do desconforto ético e moral com a violação dos direitos humanos. E, por fim, o receio de que tais argumentos se voltem ao protecionismo, o que afeta às exportações dos países em desenvolvimento.

A relação existente entre o comércio e os direitos trabalhistas no âmbito internacional leva em consideração o nível de desenvolvimento dos países. Isto porque nos países em desenvolvimento a mão-de-obra tende a ser menos onerosa do que nos países desenvolvidos, onde as leis trabalhistas são mais brandas. Diante disso, é correto concluir que as empresas que atuam em países desenvolvidos buscam mão-de-obra de em locais em desenvolvimento, o que torna mais atraente o preço do produto final.

Ou seja, ao invés de buscar o desenvolvimento para se alcançar os mesmos padrões sociais nos países subdesenvolvidos, há uma inversão de valores, pois os países desenvolvidos enxergam aqueles como uma oportunidade para redução de custo, deixando de empregar os nacionais de seu próprio país.

A cláusula social mescla a preocupação com a concorrência desleal, trazendo uma resposta política à opinião pública sobre o problema do desemprego estrutural nos países desenvolvidos, em razão da lógica globalizada, além de levantar o debate concernente aos direitos humanos no campo dos direitos laborais (LAFER, 1998, p. 35).

Pelo raciocínio lógico, tendo em vista a exploração dos países em desenvolvimento, há forte receio das práticas protecionistas, bem como dos prejuízos aos direitos nos países em desenvolvimento. Pois, embora possa se argumentar a geração de empregos nos países subdesenvolvidos, em verdade a riqueza produzida não é, via de regra, implementada em prol daquela sociedade, mas sim revertido ao país de origem (desenvolvido). 
Em que pese a existência de controvérsias sobre o tema nas negociações internacionais da OMC, os Estados Unidos da América e a Noruega são os maiores defensores da medida, que buscam a fixação de padrões mínimos trabalhistas para fins de comércio internacional, embora não tenha sido especificamente objeto de negociação das rodadas internacionais.

Em contraponto a este posicionamento, os países em desenvolvimento, que não concordam com esta cláusula social, sustentam que estabelecer padrões trabalhistas europeus geraria rigidez ao mercado de trabalho e enfraqueceria o comercio internacional dos países em desenvolvimento.

Modena destaca duas vertentes sobre as cláusulas sociais, uma positiva e outra negativa:

(...) considera-se que as cláusulas sociais atuam em duas vertentes. A primeira, de maneira negativa, prevê a aplicação de sanções punitivas ao país que não exige dos empregadores que seus trabalhadores laborem em condições dignas, bem como, a utilização da cláusula social como instrumento de protecionismo de mercados por parte dos países desenvolvidos. A segunda, de cunho positivo, premia aqueles países que cumprem as determinações das cláusulas sociais, colocando-os em posição favorável no comércio internacional por cumprirem normas de proteção aos seus trabalhadores e por evitarem que, na cadeia produtiva, formas degradantes de trabalho sejam utilizadas (MODENA, 2010, p. 133).

Todavia, a controvérsia da relação entre comércio internacional e os direitos trabalhistas, para além dos aspectos positivos e negativos na esfera comercial, reflete, também, na questão de competência para as tratativas sobre a matéria, como estabelecido na Declaração Ministerial da OMC, na Rodada Cingapura de 1996:

A OIT - Organização Internacional do Trabalho - é o órgão competente para estabelecer essas normas e ocupar-se delas, e afirmando nosso apoio a sua atividade de promoção das mesmas. Consideramos que o crescimento e o desenvolvimento econômico, impulsionados pelo incremento do comércio e pela maior liberalização comercial contribuíram para a promoção dessas normas. Rechaçamos a utilização das normas de trabalho com fins de protecionismo e concordamos que não se deve em absoluto a vantagem comparativa dos países, em particular, dos países em desenvolvimento e seus baixos salários. A esse respeito tomamos nota de que as secretarias da OMC e da OIT prosseguirão com suas atuais colaborações. 
De acordo com Amaral Junior (1999, p. 10), a OMC tem competência meramente punitiva no que concerne a práticas comerciais e, ao tratar de direitos trabalhistas, deverá se passar, invariavelmente pelas noções de direitos humanos. Seria equiparar os direitos humanos a expedientes econômicos voltados ao aumento da competitividade, em razão do desvirtuamento das regras de mercado, e não visualizar como obstáculo à realização da dignidade humana.

Não obstante a isso, tem-se que há dois pontos de vista defendidos sobre a implementação ou não da cláusula social. De um lado, o posicionamento dos países desenvolvidos é no sentido de impor padrões trabalhistas mais abrangentes a fim de superar a concorrência desleal advinda do baixo custo com direitos laborais. E, por outro lado, os países em desenvolvimento, argumentam que há mascarada estratégia protecionista dos países desenvolvidos.

Nota-se, portanto que a fixação da cláusula social, envolve discussões inicialmente sobre a competência do órgão responsável para tratar do tema em âmbito internacional, restando dividido entre a OMC e a OIT.

A oposição pela implementação da cláusula social, em geral de países em desenvolvimento, destacam o alto custo dos padrões trabalhistas e a perda para a concorrência dos países desenvolvidos. Estes últimos, que advogam em defesa da implementação da cláusula, destacam justamente a necessidade de fixação de parâmetros mínimos de direitos trabalhistas, a fim de obstar a concorrência desleal das empresas que se fixam em países subdesenvolvidos.

Além disso, o que deve ser salientado é que a perspectiva sobre a qual os países estão analisando o tema é meramente comercial, sendo que a proteção, neste caso, deve ser dos trabalhadores e da sociedade. Ou seja, para além da punibilidade em favor do prejudicado pela concorrência desleal, há que se incluir no debate a reparação de danos aos próprios trabalhadores, o que não vem sendo incluído na pauta de rodadas das negociações internacionais.

Assim, diante das controvérsias instaladas, tem-se que a competência para tratar do assunto deve prever a atuação conjunta tanto da OMC quanto da OIT, para fusionar atos comerciais e direitos laborais. E, para além da punibilidade pelo ato de concorrência desleal, a temática deve prosseguir a fim de que não só o ilícito comercial seja punido, mas também, senão principalmente, sejam reparados os danos sociais praticados no âmbito trabalhista. 


\section{CONSIDERAÇÕES FINAIS}

Consoante visto, o dumping é um ato de concorrência desleal, definido como prática comercial, através da qual uma empresa passa a vender mercadorias em preço inferior ao do mercado interno, com o objetivo lesar seus concorrentes.

As medidas antidumping estão inseridas no Artigo VI, do Acordo Geral Sobre Tarifas Aduaneiras e Comércio 1947 apresentando o regramento de compensações decorrentes desses atos anticoncorrenciais.

As medidas compensatórias são definidas como um montante em dinheiro, igual ou inferior à margem de dumping apurada, que é exigido a fim de afastar os efeitos danosos às empresas concorrentes que sofreram com o ato desleal.

Conforme delineado neste trabalho, o dumping social é conceituado como a busca de empresas por vantagens de custo mais baixo referente à mão-de-obra e a tributos, através da fixação de salários reduzidos e de condições precárias de trabalho.

O dumping social apresenta uma dualidade, pois além de ser um ato de concorrência desleal, afronta todos os aspectos atinentes às condições de trabalho violando direitos fundamentais.

O tema foi inserido em pauta perante a Organização Mundial do Comércio (OMC), com a proposta de implementação de uma cláusula social nas transações internacionais. A cláusula social seria uma espécie de medida antidumping social de maneira preventiva. Porém, ainda não há definição completa diante de uma série de debates gerados.

Diante disso, a cláusula social seria plenamente apta a produzir efeitos, contudo devem, antes disso, serem sanadas algumas controvérsias, tais como, a competência para tratar do assunto e a punibilidade pelo ato de concorrência desleal, considerando que devem ser reparados os danos sociais praticados, além da esfera comercial, no âmbito trabalhista.

\section{REFERÊNCIAS}

Acordos da OMC. Disponível em: <http://www.mdic.gov.br/index.php/comercioexterior/negociacoes-internacionais/1885-omc-acordos-da-omc>. Acesso em: 12.Set.2019.

AMARAL JÚNIOR, Alberto do. Cláusula social e comércio internacional. In: AMARAL JÚNIOR, Alberto do; PERRONE-MOISÉS, Cláudia (orgs.). O cinquentenário da declaração universal dos direitos do homem. São Paulo: Editora da Universidade de São Paulo, 1999. 
BARRAL, Welber. Dumping e comércio internacional: a regulamentação antidumping após a Rodada Uruguai. Rio de Janeiro: Forense, 2000, p. 16-71.

BARRETO, Pedro Henrique. História - Bretton Woods. Disponível em: $<$ http://www.ipea.gov.br/desafios/index.php?option=com_content\&view=article\&id=2247:cat $\mathrm{id}=28 \&$ Itemid=23>. Acesso em 11.Set.2019.

CASAGANDE, Lilian Patrícia; ANTUNES, Terezinha Cristina Meurer. O dumpring social e a proteção aos direitos sociais dos trabalhadores In Cadernos do Programa de PósGraduação em Direito/UFRGS. Volume IX, n. 2, 2014.

Declaração Ministerial da Organização Mundial do Comércio. Rodada Cingapura, 1996.

FRAHM Catarina; VILlATORE Marco Antônio César. Dumping social e o Direito do Trabalho. Disponível em: <http://www.scribd.com>. Acesso em: 30 jun. 2011.

FRANCO. Karina Marzano. Desenvolvimento e Comércio: a Viabilidade de uma Cláusula Social na OMC In V Anuário brasileiro de direito internacional. Belo Horizonte: CEDIN, 2006

GAVA, Rodrigo. Ricos \& Mendazes - O Dilema das Cláusulas Sociais nas Relações Multilaterais de Comércio Internacional (Um Itinerário Sinuoso-Bloqueante para o Direito ao Desenvolvimento). Edições Almedina: 2008.

GRANGER, Clotilde; SIROEN, Jean-Marc. Core Labor Standards in Trade Agreements. From Multilateralism to Bilateralism. Université Paris Dauphine, Département d'Économie Appliqué. Disponível em: <http://www.iddri.org/Activites/Conferencesinternationales/21102005_CAT\&E_siroen_com.pdf>. Acesso em: 11.Set.2019.

LAFER, Celso. A OMC e a regulamentação do comércio internacional. Porto Alegre: Livraria do Advogado, 1998.

LÔBO, Marcelo Jatobá. Direitos Antidumping. São Paulo: QuartierLatin, 2007.

MARQUES, Frederico do Valle Magalhães. O "Dumping” na Organização Mundial do Comércio e no Direito Brasileiro - Decreto n. 1.602/95. In: CASELLA, Paulo Borba; MERCADANTE, Araminta de Azevedo. (coord.) Guerra comercial ou integração mundial pelo comércio?: a OMC e o Brasil. São Paulo: LTr, 1998.

MODENA, Ana Isabel. As cláusulas sociais como instrumento de efetividade dos direitos fundamentais do trabalho. Dissertação apresentada ao Programa de Pós-graduação em Direito como requisito parcial para a obtenção do Título de Mestre em Direito Constitucional. Universidade de Fortaleza. 2010.

RATTI, Bruno. Comércio internacional e câmbio. 10. Ed. São Paulo: Aduaneiras, 2001.

ROCHA DA SILVA, Alice. Dumping e direito internacional econômico. Revista do Programa de Mestrado em Direito do UniCEUB, Brasília, v. 2, n. 2, p.390-417, jul./dez. 2005.

Social na OMC In V Anuário brasileiro de direito internacional. Belo Horizonte: CEDIN, 2006. 
TEIXEIRA, Leandro Fernandez. A prática de dumping social como um fundamento de legitimação de punitive damages, em uma perspectiva da análise econômica do direito. 2012. 236 p. Dissertação-(Mestrado em Relações Sociais e Novos Direitos). Universidade Federal da Bahia, Salvador, 2012.

VILLATORE, Marco Antônio César; GUNTHER, Luiz Eduardo. GLOBALIZATION, ECONOMIC CRISIS AND COLLECTIVE BARGAINING IN INTERNATIONAL LABOR LAW. Revista Juridica, [S.1.], v. 51, n. 2, p. 137 - 165, abr. 2018. ISSN 2316-753X. Disponível em: <http://revista.unicuritiba.edu.br/index.php/RevJur/article/view/2803/371371471>. Acesso em: 20 abr. 2020. doi:http://dx.doi.org/10.21902/revistajur.2316-753X.v51i2.2803. 